\title{
Hemostatic state augmented with platelet indices among Sudanese diabetic septic foot
}

Bashir Abdrhman Bashir ${ }^{*}$ and Mohamed Salih Ali

\begin{abstract}
Background: Diabetes mellitus is a very rampant metabolic disorder, particularly type II. It has many complications such as the septic foot. Diabetic septic foot (DSF) patients are at high risk for coagulation abnormalities as well as surgical hazards. Owing to the potential sequelae of coagulation and vascular abnormalities, this work aimed at studying the hemostatic state and platelet indices in diabetes type II patients with septic foot.

Methods: A case-control study was conducted during the period from July to September 2017 at Dr. Awaad medical center, Red Sea State, Sudan. 57 diabetic patients with septic foot, aged between 17 and 78 years along with 57 non-diabetic subjects as control were enrolled. Sociodemographic data were collected using a structured questionnaire. Venipuncture blood was taken with necessary safety measures. Diabetes profile, coagulation studies as well as platelet indices were estimated. Data was analyzed using SPSS version 24.0 for windows. Ethical approval was considered and written consent from each participant was obtained.
\end{abstract}

Results: The mean age of diabetic patients with septic foot and healthy controls were $48.49 \pm 15.8$ and $32.77 \pm 14.0$, respectively. The duration of the diabetes onset was $10.43 \pm 9.5$ years. Plasma prothrombin time (PT) value (12.61 \pm 2.6 vs $13.67 \pm 1.5, P<0.009$ ) was found to be significantly shorter in DSF compared to control. Plasma activated partial thromboplastin time (APTT) value was significant in diabetic septic foot $(32.64 \pm 5.2$ vs $28.49 \pm 4.13, P<0.000)$, and thrombin time (TT) did not changed in DSF. Mean platelet volume (MPV), platelet distribution width (PDW), and platelet large cell ratio (P-LCR) values were significantly decreased in DSF compared to control $(P<0.013,0.034$, and 0.020, respectively). PDW values were positively correlated with PT, APTT, and D-Dimer (DD) $(r=0.28 / p<0.003$, $r=0.29 / p<0.029$, and $r=0.32 / p<0.016$, respectively). FVIII activity $(121.86 \pm 174.4$ vs $98.66 \pm 31.83, P<0.951)$ was insignificant with DSF, as the DD was also insignificant $(P<0.081)$.

Conclusion: Diabetes mellitus is associated with prothrombotic tendency. Hypercoagulable state in DSF is indicated by shortened PT finding. PDW is a manifesting evidence that proves the presence of more reactive and aggregable platelets in DSF patients.

Keywords: Diabetes, Coagulation, DSF, Platelet indices, Sudan

\footnotetext{
*Correspondence: bashirbashir17@hotmail.com

Hematology department, Port Sudan Ahlia College, Port Sudan, Sudan
}

(c) The Author(s). 2018 Open Access This article is distributed under the terms of the Creative Commons Attribution 4.0 International License (http://creativecommons.org/licenses/by/4.0/), which permits unrestricted use, distribution, and reproduction in any medium, provided you give appropriate credit to the original author(s) and the source, provide a link to the Creative Commons license, and indicate if changes were made. The Creative Commons Public Domain Dedication waiver (http://creativecommons.org/publicdomain/zero/1.0/) applies to the data made available in this article, unless otherwise stated. 


\section{Background}

Globally, diabetes mellitus is rising, the prevalence is steadily increasing everywhere, mostly in the middleincome countries [1]. The prevalence in rural Sudan population is about $3.9 \%$, which in turn lead to an increase in the rate of admission [2]. Diabetic septic foot (DSF) is a common complication of diabetes, with an estimation that every $30 \mathrm{~s}$ a lower limb lost somewhere as a consequence of complication of DSF [3]. Eighty percent of diabetic mortality rates is due to thrombotic events. While, $75 \%$ of these mortalities belonged to cardiovascular problems and $25 \%$ remainder due to peripheral vascular events as well as cerebrovascular complications [4]. The vascular endothelium is substantially regulated of (local) hemostatic mechanism (coagulation and fibrinogen). Endothelial dysfunction has been reported in type II diabetes mellitus. A procoagulant condition is observed in diabetic patients, which ultimately contribute to cardiovascular events. Many clotting factors such as I, VII, IX, XII, Kallikrein and von Willebrand factor (VWF) are increased in diabetes [5]. This hypercoagulability could be due to an imbalance between the endothelial surface and the blood clotting factors. In type II diabetes mellitus increased level of antihemophilic factor (VIII) was observed previously with uncertain correlation to the vascular problems [6]. Some reports demonstrated insignificancy in FVIII level between diabetes type II and normal healthy individual. Thus, high levels of FVIII are more evident in the presence of increased VWF concentration [7, 8]. Platelets are normal in both diabetic and non-diabetic individuals. Recent reports have shown significant changes in platelet parameters in diabetic patients when compared with controls, particularly the mean platelet volume (MPV) and platelet distribution width (PDW) [9]. These reports suggest that platelets with variable morphology could be associated with an increased risk of vascular complications in diabetes [9]. Hyperglycemia, in turn, may contribute to endothelial dysfunction and vascular damage. This condition exerts an increase platelet reactivity and promotes glycosylation of platelet proteins [10]. This study was designed to evaluate the alteration in coagulation parameters and platelet indices and their relation to diabetic septic foot in Sudanese patients.

\section{Methods}

\section{Study design and subjects}

A case- control study was carried out among patients with diabetes type II presented with diabetic septic foot (DSF) at the Dr. Awaad Medical Centre (private sector clinic), Red Sea State, Sudan. 57 patients confirmed diabetic with septic foot were recruited in the study along with 57 non-diabetic healthy individual. Diabetic patient with septic foot for a long duration at least one month was enrolled in this study. Diabetic subjects who had clinical or laboratory signs of malignancy, coagulation disorders, liver impairment, cardiovascular diseases, or receiving medication that could affect the platelets and coagulation system were excluded. Prothrombin time (PT), activated partial thromboplastin time (APTT), thrombin time (TT), factor VIII, D-Dimer (DD), fasting blood glucose (FBG), glycosylated hemoglobin (Hb A1c) and platelet indices were screened in this study.

\section{Socio-demographic data}

A structured questionnaire was utilized to collect the data from diabetic septic foot patients [11]. The questionnaire includes age, sex, duration of the disease and drug administration prior to specimen collection.

\section{Study sample}

Open Epi calculator for case-control study was used to determine the sampling size. The standard normal variant for the power of the study is $80 \%$ where, the control exposure was measured at $23 \%$ [12]. The minimum sample size calculated for this study was 57 .

\section{Sampling technique}

A venipuncture vacuum tube method was used to collect blood sample in the morning between 8.00-9.00 a.m. after at least $12 \mathrm{~h}$ fasting. $3 \mathrm{ml}$ added to vacutainer bottle containing di-potassium ethylene diamine tetra acetic acid $\left(\mathrm{K}_{2}\right.$-EDTA) according to the international committee (council) of standardization in Hematology (ICSH) recommends. $3 \mathrm{ml}$ was collected in fluoride oxalate vacutainer for (FBS) measured by URIT 810 semiautomated chemistry analyzer. $2.7 \mathrm{ml}$ was dispensed into vacutainer bottle containing tri-sodium citrate (0.109 M) as the third sample. An aliquot of plasma was transferred into another plastic tube and promptly performed the PT, APTT, and TT (by URIT coagulometer analyzer). The remainder was frozen in $-80 \%{ }^{\circ} \mathrm{C}$ until assayed for factor VIII and D-Dimer levels. Platelets indices were measured immediately with semi-automated hematology counter (Sysmex KX-21). Glycosylated hemoglobin was estimated by NycoCard $^{\circledR}$ method using NycoCard $^{\circ}$ READER II (SN 67498, Axis-Shield PoC AS, Oslo, Norway).

\section{Data statistical analysis}

Data of coagulation and platelet indices were estimated stepwise by comparing mean student t-test and Chisquare test. The probability value $<0.05$ was taken as the minimum level of statistical significance. The findings were presented as mean \pm SD. Statistical package for the social science for windows 10 (SPSS version 24, IBN, USA) was used for the statistical analysis. 


\section{Results}

Fifty-seven DFS patients 33 (57.9\%) were males and 24 (42.1\%) were females, with the mean age being $48.49 \pm$ 15.8 years. Among the 57 controls 44 (77.2\%) were males and $14(22.8 \%)$ were females with the mean age being $32.77 \pm 14.0$ years. The laboratory characteristics for all participants, including diabetes profile, platelet indices, markers of coagulation and fibrinolysis are presented in Table 1. The duration of the diabetes was 10 . $43 \pm 9.7$ years and positively correlated with age, sex, APTT, DD, PDW, and P-LCR $(r=0.39 / p<0.003, r=-0$. $33 / p<0.014, r=0.27 / p<0.043, r=0.30 / p<0.024, r=0$. $31 / p<0.019$, and $\mathrm{r}=0.27 / p<0.040$, respectively).

In the present study, FBG and HbA1c values were found to be significantly higher in DSF patients when compared to control $(P<0.000)$ and positively correlated with APTT $(r=0.37, p<0.004)$ and negatively correlated with PT, TT, FVIII, DD, PLT, MPV, PDW, PCT and PLCR $(r=-0.80 / p<0.386, r=-0.11 / p<0.909, r=0.17 / p$ $<0.119, r=13 / p<0.338, r=0.22 / p<0.051, r=0.18 / p<0$. $052, r=0.96 / p<0.377, \mathrm{r}=0.18 / p<0.174, r=-0.92 / p<0$. 299 , respectively).

\section{Platelet indices}

Platelet parameters in diabetic patients with septic foot in comparison to the control were found to be significantly different in PLT, MPV, PDW, PCT, and PLCR $(P<0.001,0.013,0.034,0.011$, and 0.020 , respectively). Furthermore, the MPV, PDW, and P-LCR were lower in DSF than the control. While PLT and PCT were higher in DSF as compared with the controls (Table 1).

PDW value has been recognized as an evidence of platelet activity and was significantly correlated with PT, APTT, DD, and PLT $(r=0.28 / p<0.003, r=0.29 / p<0$. $029, r=0.32 / p<0.016$, and $r=-0.24 / p<0.010$, respectively). Platelet count also correlated positively with MPV, PDW, PCT, and P-LCR $(r=-0.29 / p<0.002, \mathrm{r}=-0.24 / \mathrm{p}$ $<0.010, r=0.95 / p<0.000, r=-0.30 / p<0.001)$ and negatively with PT, APTT, TT, VIII, and DD $(r=-0.07 / p<0$. 442, $r=-0.12 / p<0.194, r=-0.10 / p<0.302, r=-0.144 /$ $p<0.284$, and $r=-0.06 / p<0.638$, respectively). PLT and PCT values were increased in DSF patients as compared with the non-diabetic subjects.

\section{Common coagulation tests}

In this study, the plasma prothrombin time and activated partial thromboplastin time levels were significant in diabetic septic foot compared to the control $(P<0$. 009 and 0.000). Whereas the thrombin time coagulation test was insignificant (0.801). 50.9\% of the DSF patients had shortened PT $(<12.0 \mathrm{~s})$ indicating that there is a significant effect of the disease on PT results. PT value was

Table 1 Laboratory characteristics of control and diabetic septic foot

\begin{tabular}{|c|c|c|c|}
\hline & Controls (mean \pm SD) & $\mathrm{DSF}($ mean $\pm \mathrm{SD})$ & $P$. value \\
\hline \multicolumn{4}{|l|}{ Demographics } \\
\hline Participants & 57 & 57 & - \\
\hline Age (years) & $32.77 \pm 14.0$ & $48.49 \pm 15.8$ & 0.000 \\
\hline Sex (Male/Female) & $44 / 13$ & $33 / 24$ & 0.028 \\
\hline Duration of diabetes (years) & - & $10.43 \pm 9.7$ & - \\
\hline \multicolumn{4}{|l|}{ Diabetes profile } \\
\hline FBS & $94.19 \pm 14.2$ & $209.01 \pm 96.0$ & 0.000 \\
\hline $\mathrm{HbA1c}$ & $3.77 \pm 0.57$ & $8.36 \pm 3.84$ & 0.000 \\
\hline \multicolumn{4}{|l|}{ Platelet parameters } \\
\hline $\mathrm{PLT} \times 10^{3} / \mu \mathrm{l}$ & $218.24 \pm 67.6$ & $270.78 \pm 94.0$ & 0.001 \\
\hline MPV fl & $10.44 \pm 0.99$ & $9.95 \pm 1.06$ & 0.013 \\
\hline PDW fl & $13.99 \pm 2.34$ & $13.07 \pm 2.23$ & 0.034 \\
\hline PCT \% & $0.227 \pm 0.07$ & $0.266 \pm 0.09$ & 0.011 \\
\hline P-LCR \% & $28.83 \pm 7.30$ & $25.61 \pm 7.24$ & 0.020 \\
\hline \multicolumn{4}{|l|}{ Common Coagulation tests } \\
\hline PT second & $13.67 \pm 1.59$ & $12.61 \pm 2.57$ & 0.009 \\
\hline APTT second & $28.49 \pm 4.13$ & $32.64 \pm 5.20$ & 0.000 \\
\hline TT second & $16.26 \pm 2.43$ & $16.14 \pm 2.31$ & 0.801 \\
\hline \multicolumn{4}{|l|}{ Special Coagulation Studies } \\
\hline $\mathrm{DD} \mathrm{ng} / \mathrm{ml}$ & $150.61 \pm 52.98$ & $130.81 \pm 81.54$ & 0.081 \\
\hline FVIII \% & $98.66 \pm 31.83$ & $121.86 \pm 174.8$ & 0.951 \\
\hline
\end{tabular}


correlated positively with APTT, PDW, P-LCR $(r=0.28$, $P<0.003)$, and MPV $(r=0.20, P<0.038)$. The statistical details of the coagulation tests are illustrated in Table 2.

\section{Special coagulation studies}

However, the concentration of DD showed decreased levels for DSF patients in comparison with the control $(130.81 \pm 81.54$ vs $150.61 \pm 52.98)$. In contrast, factor VIII concentration demonstrated increased levels in DSF $(121.86 \pm 174.8$ vs $98.66 \pm 31.83)$, although it was insignificant $(P<0.951)$ as depicted in Table 1 .

\section{Discussion}

Diabetes impairs the coagulation homeostasis which cause vascular thrombotic events [13]. In this study, we focused on the alteration of coagulation and platelet parameters that associated with the diabetic patients with septic foot. Few reports are available regarding the coagulation studies and platelet indices in diabetes, particularly in our area. The diabetic complication and its severity are depending on the duration of the disease onset [14], this observation was highlighted in our study.

With regard to platelet indices which represent as new insight in diagnosis and prediction of the platelet activity, the MPV, PDW, PCT, and P-LCR values were observed statistically significant in this study. The MPV denotes the platelet average size and activity [15]. Large platelets are younger and more potent to secrete more thromboxane $\mathrm{A}_{2}$ and serotonin than the small platelet [16]. The MPV and PDW were found significant in association with septic foot (microvascular injury), this may support the clue that the presence of more reactive and aggregable platelet is a factor involved in the progression of diabetes complications. These findings are similar to Alhadas and Santos et al. [15]. In fact, many authors have studied the MPV changes associated with diabetes. Among these reports, the MPV findings were controversial $[16,17]$. High blood glucose values were also considered a factor that involved in augments in platelet reactivity, because it has direct effects on platelet and promotes platelet protein glycosylation [9]. However, the high MPV in diabetes is a finding that could predict thrombotic events [10]. With respect to PDW, there is an evidence in the literature that PDW is a potential marker in diabetes. Platelet activation was noted significantly, and correlated positively with PT, and DD. These results were agreed with a previous study [18] reported that PDW gives an account in diabetes on the platelet activity. The activated platelet had increased the number and size of the pseudopodia and this may possibly lead to alteration in the PDW, as expressed by Bashir et al. [15]. Moreover, many significant differences were found in PDW value in diabetic patients with septic foot when compared to other diabetic complications, a finding that is corroborated with Alhadas et al. [19] and Jindal et al. [9] and contrarily with Chen et al. who reported that there was no relation between PDW and diabetes [20]. However, the discordant findings in this study may probably be accounted to the fact that most of the diabetic had been on treatment for varying durations, particularly the antiplatelet drugs such as clopidogrel rather than the aspirin which is used constitutively to the patients, although we have excluded the patients that administrated antiplatelet medications. This could be one of the possible limitation of the study. As well, some factors may have influenced the MPV and PDW such as the platelet proliferation and turnover, platelet survival time, and poor glycemic control in type II diabetes mellitus [21].

The short result of prothrombin time and activated partial thromboplastin time predisposes the patients to high risk of thrombosis [22]. So, the risk may be increased folds on the diabetic septic foot [12]. Many researches have been demonstrated the abnormalities in the coagulation occur in association with the spectrum of diabetes mellitus, resulting a thrombophilic event [23]. A significant shortened PT results were detected in the present study in comparison with control. These findings are agreed with Erem $\mathrm{C}$, et al., [5] in a study conducted in Turkey to investigate the markers of coagulation and fibrinolysis in type II diabetic patients and their results determined that the levels of fibrinogen, antithrombin, plasminogen activator inhibitor-1 (PAI-1), von Willebrand factor activity and PT were found to be significantly shorter in the type II diabetic patients in

Table 2 Findings of coagulation studies

\begin{tabular}{|c|c|c|c|c|c|}
\hline Character/Parameters & PT $(n=57)$ & $\mathrm{APTT}(n=57)$ & $\Pi(n=57)$ & FVIII $(n=57)$ & $\mathrm{DD}(n=57)$ \\
\hline Short (low) & 29 (50.9\%) & $4(7.0 \%)$ & - & $21(36.8 \%)$ & - \\
\hline Normal & 25 (43.9\%) & $44(77.2 \%)$ & $55(96.5 \%)$ & $26(45.6 \%)$ & $51(89.5 \%)$ \\
\hline Prolong (high) & $3(5.3 \%)$ & $9(15.8 \%)$ & $2(3.5 \%)$ & $10(17.5 \%)$ & $6(10.5 \%)$ \\
\hline Median & 11.9 & 31.8 & 15.8 & 79.5 & 115 \\
\hline Range of test & $10.1-25.4$ & $24.1-44.3$ & $13.0-25.0$ & $14-1127$ & $40-450$ \\
\hline Range of control & $10.0-16.5$ & $20.1-38.9$ & $11.0-22.2$ & $38-456$ & $36-200$ \\
\hline Normal range & $12-16$ & $26-39$ & $<22$ & $50-150$ & $<200$ \\
\hline
\end{tabular}


compared with the control subjects. Also, Madan et al. [24] who demonstrated that PT was short in diabetic individuals. The current study also revealed a significant difference in the activated partial thromboplastin time in diabetic septic foot patients, although most value was in the normal limits. Our results are consistent with many previous works $[23,25,26]$. The thrombin clotting time did not change in our diabetic septic foot patients, a finding that is considerably similar to Erem C, et al. [5].

FVIII has been reported to be increased in patient with type II diabetes. This augmentation may be relevant to the presence of endothelial dysfunction or inflammatory condition [27]. 95\% of FVIII circulates linked with von Willebrand factor (VWF). Only 5\% of FVIII circulates freely. FVIII is increased in most inflammatory states. Moreover, it is believed that this inevitably due to VWF increases, since the FVIII formation is not influenced by inflammation [28]. Elevation of FVIII levels is considered an autonomous risk factor for thromboembolism [29]. In this report, factor VIII activity showed no significant difference between diabetic septic foot patients and controls. Various studies expressed FVIII normal, increased, and decreased [13, 24, 30]. Uncontrolled diabetes acts on the fibrinolysis by stimulating the production of PAI1. This state enhances the permanence of the clot and consequently the thrombi developed [31]. Many researches in diabetic patients revealed increased levels of DD. However, when hypercoagulability state is present there is hyperfibrinolysis consequent. Accordingly, hypercoagulability and hypofibrinolysis states are occurring in diabetic patients and the DD become underestimated [32]. Furthermore, the more rigid fibrin that result from glycated fibrinogen in a hyperglycemic patient may again contribute to decreased value, as this fibrin is difficult to be degraded [30]. DD levels in the present study are insignificant and most of values are within the normal limits. Based on the present findings, and various previous studies, the hyperglycemia has been taken to be the causative agent of abnormalities of coagulation along with vascular complication. Future studies should be expanded to evaluate platelet function, markers of endothelial injury and hypercoagulability markers.

\section{Conclusion}

It is important to know that diabetes is associated with prothrombotic state. Hypercoagulability was indicated in DSF by shortened PT. PDW is a manifesting evidence that proves the presence of more reactive and aggregable platelets in DSF patients.

\section{Abbreviations}

APTT: Activated partial thromboplastin time; DD: D-dimer; DSF: Diabetic septic food; FFBG: Fasting blood glucose; HbA1c: Glycosylated hemoglobin; MPV: Mean platelet volume; PAI-1: Plasminogen activator inhibitor-1; PCT: Plateletcrit; PDW: Platelet distribution width; P-LCR: Platelet large cell ration; PLT: Platelet count; PT: Prothrombin time; SPSS: Statistical package for social science.; TT: Thrombin time; WWF: Von willebrand factor

\section{Acknowledgements}

The authors would also like to acknowledge the Dr. Awaad medical center for their support in conducting interviews of patients and the ministry of health ethics committee for their approval to conduct this study.

\section{Availability of data and materials}

The datasets generated during and/or analyzed in this study are not publicly available due to Dr. Awaad clinic ethical policy in order to protect participant confidentiality.

\section{Authors' contributions}

BA and MS contributed in literature search and manuscript writing. BA had the main idea of the study and contributed in manuscript writing, MS contributed to Dr. Awaad medical clinic work. BA contributed in statistical analysis. BA supervised the study \& critically reviewed the manuscript. Both authors read and approved the final draft of the manuscript.

\section{Ethics approval and consent to participate}

Approval of this study was obtained from the hematology department of medical laboratory science (MLS), Port Sudan Ahlia College, Dr. Awaad medical center, and ministry of health issued by the local ethical committee, Red Sea State, Sudan. Written consent was taken from each member of the study.

\section{Competing interests}

The authors declare that they have no competing interests.

\section{Publisher's Note}

Springer Nature remains neutral with regard to jurisdictional claims in published maps and institutional affiliations.

Received: 10 September 2017 Accepted: 1 May 2018

Published online: 11 May 2018

\section{References}

1. World Health Organization. Global report in diabetes. WHO library cataloguing-in-publication data. ISBN 9789241565257 (NLM classification: WK 810), 2016.

2. Adam MA, Hamza AA, Ibrahim AE. Diabetic septic foot in Omdurman teaching hospital. Sudan J Med Sci. 2009;4(2):129-32.

3. Jeffcoate WJ, Harding KG. Diabetic septic ulcer. Lancet. 2003:361:1545-51.

4. Yamagashi S, Matsui US, Makamura K, Imaizumi T. Advanced glycation end products and cardiovascular disease in diabetes. Cardiovasc Hemat Agents Med Chem. 2007;5:236-40.

5. Erem C. Coagulation and fibrinolysis parameters in type 2 diabetic patients with and without diabetic vascular complications. Med Principl \& Pract. 2005:14:22-30.

6. Rassouli B, Ghyour MB, Ghyour N. Microvascular complication of diabetes. J Biol Sci. 2010;10:411-23.

7. Frankel DS, Meigs JB, Massaro JM, Wilson PWF, et al. von willebrand factor, type 2 diabetes and risk of cardiovascular disease. Circulation. 2008;118: 2533-9.

8. Meigs JB, O'donnell CJ, Tofler GH, Benjamin EJ, Fox CS, Lipinska I, et al. Hemostatic markers of endothelial dysfunction and risk of incident type 2 diabetes: the Framingham offspring study. Diabetes. 2006;55(2):530-7.

9. Jindal S, Gupta S, Gupta R, et al. Platelet indices in diabetes mellitus: indicators of diabetic microvascular complications. Hematology. 2011;16(2): 86-9.

10. Kodiatte TA, Manikyam UK, Rao SB, et al. Mean platelet volume in type 2 diabetes mellitus. J Lab Physicians. 2012:4(1):5-9.

11. Prianka M, Bhaskar P, Debasis D, Nilanjan S, Rachna M. Perceptions and practices of type 2 diabetecs:a cross-sectional study in a tertiary care hospital in Kolkata. Int J Diab Ctries. 2010:30:143-9.

12. Balla SA, Ahmed HA, Alhassan SF. Factor associated with diabetic septic foot among patients attending the diabetic septic foot unit in the military hospital, Khartoum state, Sudan. Saudi J Med Med Sci. 2013;1:98-102.

13. Soltani MM, Dayer MR, Ataie G, Moazedi AA. Coagulation factors evaluation in NIDDM patients. Am J Biochem Mol Biol. 2011;1(3):244-54. 
14. Askawa H, Tokunga K, Kawakami F. Elevation of fibrinogen and thrombinantithrombin III complex levels of type 2 diabetes mellitus patients with retinopathy and nephropathy. J Diabetes Complicat. 2000;14:121-6.

15. Bashir AB, Saeed OK, Mohammed BA, Ageep AK. Role of platelet indices in patients with dengue infection in Red Sea state, Sudan. IJSR. 2015:4(1):1573-6.

16. Akinsegun A, Olusola DA, Sarah JO, Olajumoke O, et al. Mean platelet volume and platelet counts in type 2 diabetes: mellitus on treatment and non-diabetic mellitus controls in Lagos, Nigeria. Pan African med J. 2014;18:42.

17. Buch A, Kaur S, Nair R, Jain A. Platelet volume indices as predictive biomarker for diabetic complications in type 2 diabetic patients. J Lab Physician. 2017;9(2):84-8.

18. Bashir BA, Dirar HH, Badneen MA. Platelet indices among Sudanese pregnant women with medical disorders association, a cross-sectional study in port Sudan city. Int J Sci. 2017;6(6):71-5.

19. Alhadas KR, Santos SN, Freitas MM, Viana SM, et al. Are platelet indices useful in evaluation of type 2 diabetic patients. J Bras Pathol Med Lab. 2016; [online]. Ahead point.PP.0-0

20. Chen $X$, Fang $L$, Lin $H$, Shen $P$, et al. The relationship between type 2 diabetes and platelet indicators. Iran J Public Health. 2017;46(9):1211-6.

21. Demirtunc $R$, Duman $D$, Basar $M$, Bilgi $M$, et al. The relationship between glycemic control and platelet activity in type 2 diabetes mellitus. J Diabetes Complicat. 2009:23(2):89-94.

22. Osaro E, Isaac IZ, Kaoji AU, John RT, Suleiman SA. Assessment of some coagulation parameters among clients on hormonal contraceptive in a tertiary health facility in Sokoto, north western, Nigeria. J Hematol Thrombo Dis. 2014;2:139.

23. Alao O, Dumulak D, Joseph D, Puepet F. Hemostatic profile of patients with type 2 diabetes mellitus in northern Nigeria. Int J Endocrinol. 2009;6:1.

24. Madan R, Gupta B, Saluja S, Kansra UC, Tripathi BK, Guliani BP. Coagulation profile in diabetes and its association with diabetic microvascular complications. J Assoc Physicians India. 2010;58:481-4.

25. Fadairo JK, Atere AD, Ogidiolu TO, Abiodun OP. Assessment of some coagulation indices among type II diabetic subjects in a tertiary facility in south west region, Nigeria. IOSR-JDMS. 2016;15(6):159-63.

26. Fathah MA, Shaheen MH. Disturbances of haemostasis in diabetes mellitus. Dis Mark J. 2004;19(6):251-8.

27. Grant PJ. Diabetes melito as a prothrombotic condition. J Intern Med. 2007; 262(2):157-72

28. Lillicrap D. Extending half-life in coagulation factors: where do we stand? Thromb Res. 2008;122(Suppl 4):S2-8.

29. Tripodi A, Mannucci PM. Laboratory investigation of thrombophilia. Clin Chem. 2001:47(9):1597-606.

30. Soares AL, Sousa MO, Fernandes AP, Carvalho MG. Hemostatic changes in patients with type 2 diabetes mellitus. Rev Bras Hematol Hemoter. 2010; 32(6):482-8

31. Lijnert RG, Collen D. Fibrinolytic system and its disorders. In: Lux SE, Stossel TP, Handin Rl, editors. Blood: principles and practice of hematology. 2ed: Philadelphia: Lippincott Williams \& Wilkins; 2003. Chapter 40. p. 1249-74.

32. Wakabayashi I, Masuda H. Association of D-dimer with microalbuminuria in patients with type 2 diabetes mellitus. J Thromb Thrombolysis. 2009;27(1): 29-35.

\section{Ready to submit your research? Choose BMC and benefit from:}

- fast, convenient online submission

- thorough peer review by experienced researchers in your field

- rapid publication on acceptance

- support for research data, including large and complex data types

- gold Open Access which fosters wider collaboration and increased citations

- maximum visibility for your research: over $100 \mathrm{M}$ website views per year

At BMC, research is always in progress.

Learn more biomedcentral.com/submissions 